\title{
SÍNDROME DO X FRÁGIL: BREVE REVISÃO E RELATO DE CASO
}

\author{
Amaral LR ${ }^{*}$, Melo HCS ${ }^{* *}$
}

\begin{abstract}
Resumo
A Síndrome do X Frágil é considerada a maior causa de retardo mental herdado, e a segunda causa genética mais comum de deficiência mental. Ela atinge todos os grupos étnicos e raças, porém tem pouca prevalência. Estima-se que a cada 1000 crianças nascidas vivas do sexo masculino, uma seja portadora da Síndrome, e que a cada 2000 crianças nascidas vivas do sexo feminino, uma seja afetada. Embora não sejam específicas, inúmeras alterações físicas e cognitivas podem ser relacionadas à Síndrome, como a deficiência mental, o dismorfismo facial e as alterações comportamentais. O objetivo com este estudo foi revisar brevemente a literatura disponível acerca da Síndrome do X Frágil e apresentar um relato de caso sobre uma criança recém-nascida diagnosticada com a doença. Para isso, bases de dados nacionais foram consultadas, e a confecção do relato clínico foi aprovada por um comitê de ética para descrever a sintomatologia inicial, os exames clínicos e a evolução da paciente com Síndrome do X Frágil a fim de auxiliar no diagnóstico de outros indivíduos que possam ter a Síndrome. É necessário que o diagnóstico da Síndrome seja feito o mais rápido possível em razão de que ela não tem cura, e
\end{abstract}

\footnotetext{
* Graduada em Biomedicina pela Faculdade Patos de Minas; laiamma@hotmail.com

** Doutor e Mestre em Genética e Bioquímica pela Universidade Federal de Uberlândia; Professor na Faculdade Patos de Minas; hugo. some@gmail.com
} 
o tratamento consiste em melhorar a qualidade e prolongar a vida do paciente afetado. $\mathrm{O}$ aconselhamento genético é indicado na maioria dos casos para evitar e prevenir novas aparições da Síndrome. Palavras-chave: Síndrome de Martin-Bell. Revisão. Registros médicos.

\title{
$X$ Fragile Syndrome: brief review and case report
}

\begin{abstract}
$X$ Fragile Syndrome is pointed as the greatest cause of inherited mental retardation, and the second most common genetic cause of mental retardation. It reaches all ethnic groups and races, but with low prevalence. It is estimated that one on every 1000 male births carries the syndrome and that one on every 2000 female born alive is affected. Although not specific, numerous physical and cognitive changes may be related to the syndrome, such as mental deficiency, facial dysmorphism and behavioral changes. This study aimed to briefly review the available literature about X Fragile Syndrome and present a case report of a newborn diagnosed with the disease. Thus, Brazilian databases were consulted and, to assist in the diagnosis of other individuals who may have the syndrome, an ethics committee approved the clinical report in order to bring public initial symptomatology, clinical exams and evolution of a patient with $X$ Fragile Syndrome. It is necessary to acquire the syndrome's diagnosis as soon as possible, since it has no cure and the treatment consists of improving and prolonging the quality of life of the affected patient.
\end{abstract} Genetic counseling is also indicated in most cases to prevent further onset of the syndrome.

Keywords: Martin-Bell syndrome. Review. Medical records.

\section{INTRODUÇÃO}

No mundo, a Síndrome do X Frágil (SXF) ou Síndrome de Martin-Bell é a causa mais comum de retardo mental ligada à hereditariedade. É, também, a segunda causa genética mais comum de deficiência mental, sendo precedida apenas pela Síndrome de Down. ${ }^{1,2,3}$

Pesquisas realizadas durante a primeira metade do século XX ressaltam um número grande de indivíduos do sexo masculino portadores de deficiência mental. Os pesquisadores Martin e Bell relataram em 1943 o caso de uma família inglesa com vários homens afetados por retardo mental grave, sendo todos filhos de mães com inteligência normal. Ao realizarem o heredrograma observaram uma herança ligada ao cromossomo $\mathrm{X}$ no gene recessivo. Por tal acontecimento, esse tipo de deficiência mental foi chamada por cerca de 30 anos de Síndrome de Martin-Bell. ${ }^{4,5}$

A SXF atinge todas as raças e grupos étnicos e tem pouca prevalência; estima-se que sua incidência seja de um afetado a cada 1000 crianças nascidas vivas do sexo masculino e de um afetado em cada 2000 crianças nascidas vivas do sexo feminino. . $^{1,3,6}$

Possivelmente, por possuírem apenas um cromossomo $\mathrm{X}$, os homens são mais susceptíveis a herdar a Síndrome do que as mulheres, que possuem dois cromossomos X, pois, no caso delas, o cro- 
mossomo sadio poderá compensar o cromossomo defeituoso. Os homens são afetados em grau mais intenso se comparado às mulheres, que, quando apresentam manifestações, estas são de grau leve. Nos primeiros anos de vida as manifestações são relacionadas principalmente ao atraso das funções motora e linguística. ${ }^{4}$

Os indivíduos do sexo masculino que possuem o cromossomo X frágil o transmitem para suas filhas, que, por sua vez, herdam a pré-mutação, porém não são afetadas pela síndrome. Quando essas mulheres tiverem filhos do sexo masculino, estes poderão ser afetados. Esse é um padrão peculiar de herança genética e é denominado de paradoxo de Sherman. ${ }^{1}$

Um número considerável de alterações físicas e cognitivas está relacionado à SXF. Entre eles pode-se destacar a deficiência mental, as alterações comportamentais, o dismorfismo facial, as anormalidades no tecido conjuntivo, o macroorquidismo, principalmente em indivíduos em idade pós-puberal, e a falha prematura ovariana em mulheres. Essas manifestações não são exclusivas aos portadores da Síndrome e podem ser compatíveis com outras desordens genéticas, portanto, sem manifestações clínicas evidentes, o diagnóstico fica impossibilitado, tornando necessária a realização de exames genéticos. ${ }^{7}$

O diagnóstico da SXF em uma criança é importante para que se faça aconselhamento genético, possibilitando identificar outros portadores e prevenir, assim, a aparição de novos casos. Os testes moleculares, especialmente o PCR, podem ser utilizados como triagem em crianças com algum tipo de retardo mental, tornando fácil a identificação da Síndrome do X Frágil ou outras síndromes genéticas. ${ }^{1}$

Essa Síndrome não tem cura, existem apenas tratamentos sintomáticos ou acompanhamento terapêutico. Utiliza-se, então, a estimulação das habilidades motoras, intelectuais e sociais visando à integração do indivíduo afetado na sociedade, de maneira a melhorar sua qualidade de vida. ${ }^{8}$

\section{METODOLOGIA}

Este artigo foi confeccionado baseado em uma revisão literária descritiva da Síndrome do X Frágil, encontrada nas bases de dados Scielo, Latindex, BVS, Google Acadêmico e PubMed, e no relato de um caso de diagnóstico de Síndrome do X Frágil em uma recém-nascida da Cidade de Patos de Minas, MG.

O relato de caso apresentado a seguir foi realizado respeitando a Resolução CNS n. 466/2012 e foi aprovado por um comitê de ética em pesquisa com seres humanos mediante parecer n. 2.304.656.

\section{REVISÃO DE LITERATURA}

\subsection{GENÉTICA}

Em 1969, pesquisadores observaram e relataram a associação entre a deficiência mental e a presença de um cromossomo X marcador. Deu-se a essa variante o nome de Cromossomo X Frágil. ${ }^{7}$ 
A expansão de um trinucleotídeo com repetições CGG na região promotora do gene FMR1 é considerada a principal causa da Síndrome do X Frágil. Indivíduos que não apresentam retardo mental e que, portanto, são considerados normais, possuem uma variação de 5 a 52 repetições, "na presença desse alelo, ocorre produção normal da proteína Fragile X Mental Retardation Protein (FMRP) e fenótipo normal." Portadores da SXF apresentam mais de 200 repetições nessa região, o que se considera uma expansão significativa. ${ }^{1,9,10}$

O gene que está localizado no braço longo do cromossomo X (Xq27.3) (Figura 1) é responsável pela codificação de, ao menos, 12 tipos diferentes de RNAm. O mecanismo de splicing alternativo origina variados tecidos, principalmente os que compõem o epitélio, o cérebro e os testículos. A expressão desse gene resulta na proteína FMRP. ${ }^{9}$

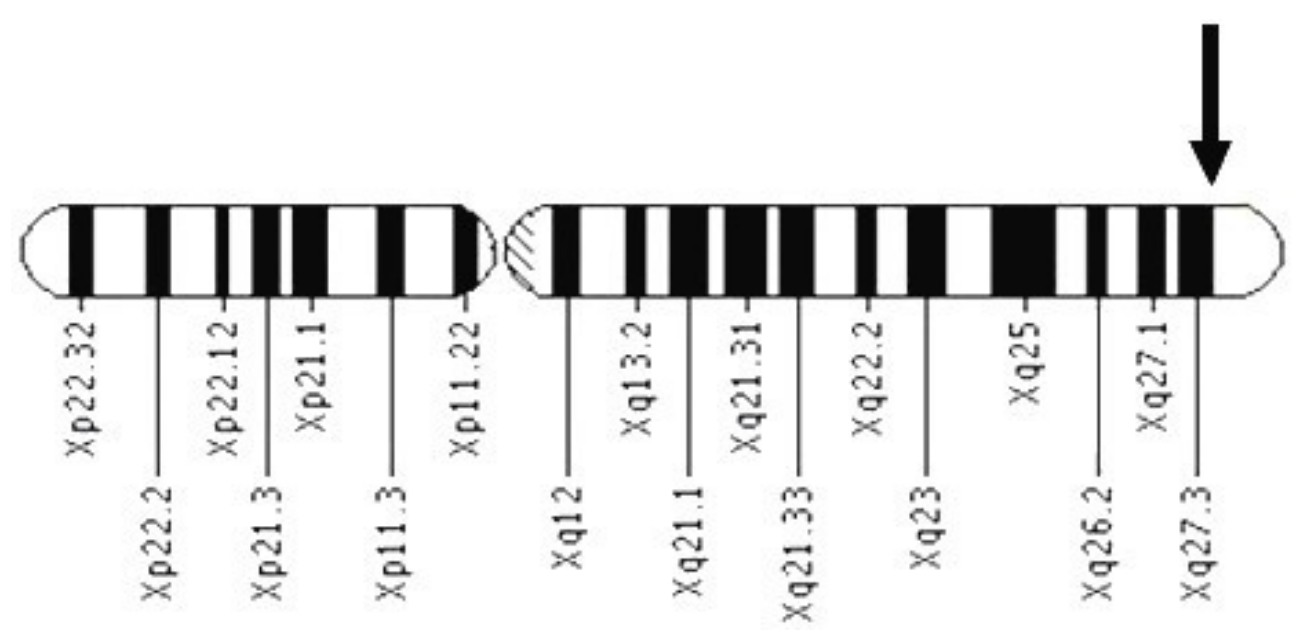

Figura 1 - Gene Xq27.3 (seta) localizado no braço longo do cromossomo X Fonte: Amaral, Sollitto, Santos, Parizi, Oliveira e Straioto. ${ }^{11}$

A metilação da região promotora, causada pelas grandes expansões, resulta na contenção do gene FMR1. Poucos pacientes portadores da Síndrome apresentam mutações no gene FMR1. Quando o número de repetições de trinucleotídeos ultrapassa 55, mas fica abaixo de 200, tem-se o que se denomina pré-mutação. ${ }^{1,10,12}$

Apesar de não apresentarem comprometimento cognitivo, os pacientes portadores da pré-mutação podem apresentar efeitos em longo prazo. A Síndrome de Tremor e Ataxia (FXTAS) é uma patologia neurológica progressiva associada à SXF e que tem início após os 50 anos de idade. Atinge homens e mulheres, mas, assim como na Síndrome do X Frágil, as mulheres são atingidas com grau menor de severidade e com menos frequência. Entre os sintomas se pode relatar tremores, rigidez, diminuição da expressão facial e lentidão nos movimentos, além de alguns problemas psiquiátricos como instabilidade, depressão e ansiedade. Ocorre um efeito tóxico do FMR1 - RNAm que é produzido em excesso, o que pode ser relacionado à clínica da FXTAS., ${ }^{9,13,14}$ 


\subsection{FISIOPATOLOGIA}

A determinação do sexo ocorre pela presença de dois cromossomos X (mulheres) ou por um cromossomo X e um cromossomo Y (homens), assim, quando ocorre a fecundação, o indivíduo herdará um cromossomo X da mãe e um cromossomo X ou Y do pai. O cromossomo X normal se apresentará de forma regular, enquanto o cromossomo $\mathrm{X}$ frágil, ao ser cultivado, apresentará as extremidades deletadas. Ainda não foi possível determinar com exatidão como essa alteração interfere na função cerebral, mas autópsias mostram que essa delação de partes do cromossomo pode mudar o número de ligações entre uma célula e outra. ${ }^{13,15}$

Sabendo que as mulheres apresentam dois cromossomos $\mathrm{X}$, acredita-se que não sejam tão afetadas pela Síndrome quanto os homens, pois um cromossomo X saudável compensa o outro defeituoso. Por terem um cromossomo X e outro Y, os homens não possuem tal mecanismo compensatório. O que difere a Síndrome do X Frágil de outras anormalidades cromossômicas é que esta não é decorrente de novas mutações. A SXF é hereditária e pode ser transmitida a qualquer geração, por exemplo, se uma mulher for portadora do cromossomo X frágil, mesmo não apresentando manifestações clínicas, pode transmitir o gene sem ter conhecimento (Figura 2). Por isso, torna-se necessário consultar um geneticista para fazer um mapeamento genético quando houver casos da Síndrome na família. ${ }^{13,15}$

As manifestações da SXF podem apresentar diferentes graus. O gene defeituoso pode apresentar de 50 a 200 cópias CGG, tornando o indivíduo portador da Síndrome e capaz de transmitir o gene para seus filhos, mas não apresentando sinais evidentes, ou pode apresentar mais de 200 cópias, sendo, assim, afetado pelos sintomas. ${ }^{13,15}$

Quando portador do gene, o homem transmitirá a pré-mutação a todas as suas filhas, mas não transmitirá o gene aos seus filhos (Figura 2). Por sua vez, as filhas transmitirão a pré-mutação a seus filhos, netos, bisnetos, etc., mesmo não apresentando alterações cognitivas, físicas, emocionais e intelectuais. ${ }^{13,15}$

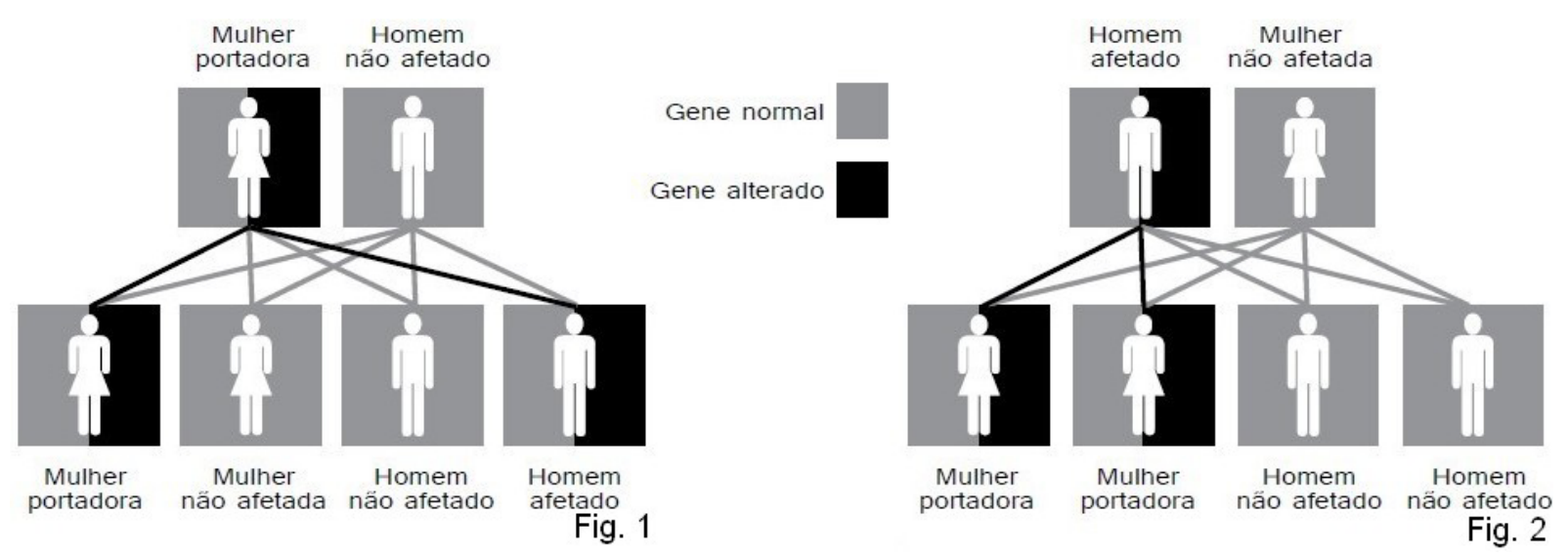

Figura 2 - Esquerda: transmissão de SXF por uma mulher; direita: transmissão de SXF por um homem Fonte: Hessl e Grigsby. ${ }^{13}$ 
Normalmente os pais são os primeiros a notar sintomas correlacionados à Síndrome do X Frágil. A idade média de aparição dos sintomas nos indivíduos do sexo masculino é de 12 meses e no sexo feminino é de 16 meses. O diagnóstico costuma ocorrer entre o $35^{\circ}$ e o $37^{\circ}$ mês para os homens (Figura 3), e para as mulheres, por apresentarem sintomatologia mais branda, aproximadamente no $42^{\circ}$ mês. ${ }^{16}$

A demora em relação ao diagnóstico deve-se ao fato de que os sintomas são pouco específicos e não muito aparentes durante os primeiros meses de vida do indivíduo, tornando-se evidentes somente à medida que o desenvolvimento intelectual e cognitivo da criança começa. Algumas pesquisas estimam que em cerca de um terço $(37,6 \%)$ das famílias em que algum membro tinha suspeita de SXF foram necessárias inúmeras visitas ao médico antes de o diagnóstico ser concluído. Decorrem aproximadamente 16 meses entre a aparição dos primeiros sintomas até o diagnóstico da Síndrome do X Frágil. ${ }^{16}$

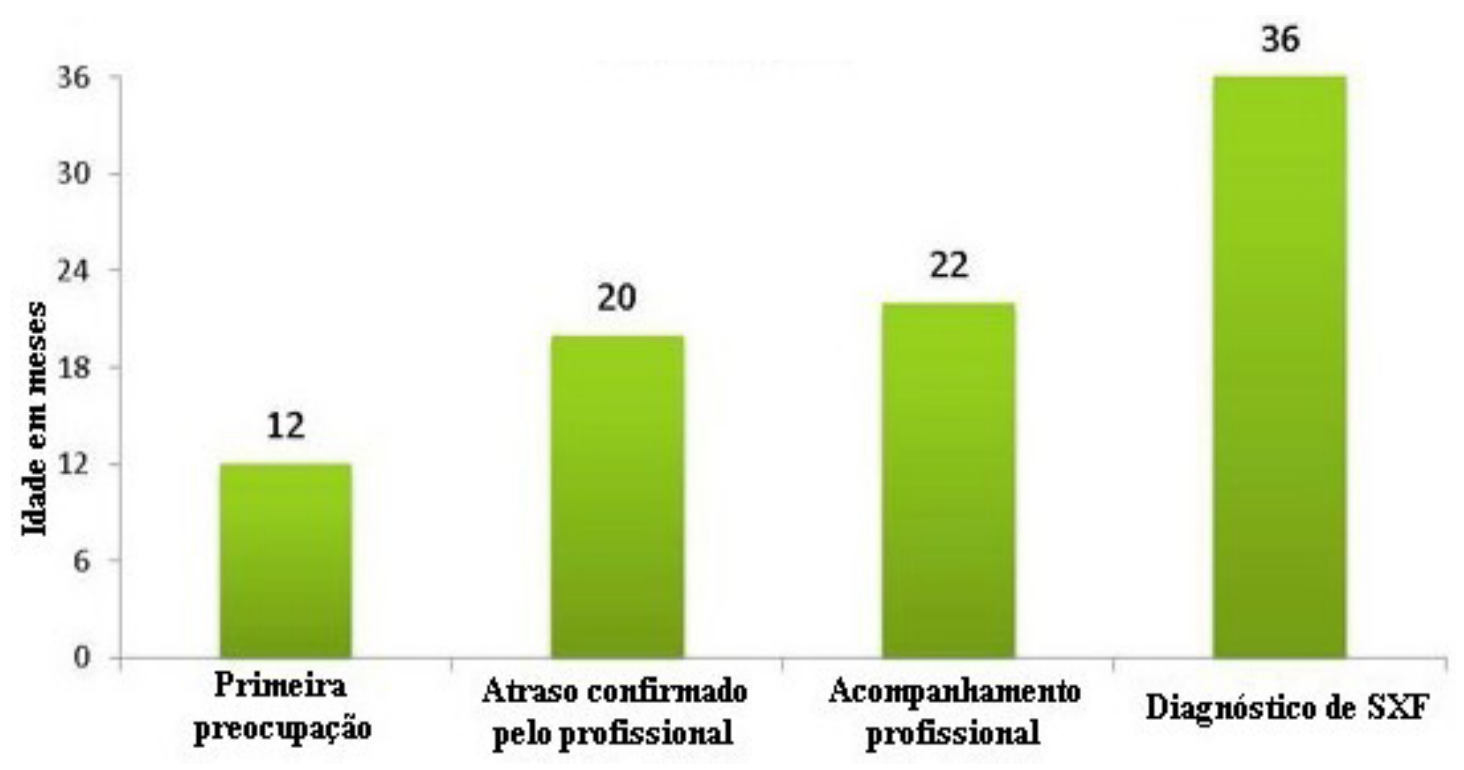

Figura 3 - Gráfico representando a idade média da primeira preocupação, atendimento profissional, confirmação, acompanhamento e diagnóstico em meninos

Fonte: Bailey, Raspa, Bishop e Holiday. ${ }^{16}$

\subsection{SINTOMAS}

A deficiência mental é considerada a maior manifestação clínica da Síndrome do X Frágil visto que as funções cognitivas e de adaptação do indivíduo ficam prejudicadas. As capacidades de aprendizado, movimentação e autoexpressão do portador da SXF tornam-se limitadas em consequência do retardo mental, o que demanda atenção com tarefas básicas para com esse indivíduo maior do que a normal. Torna-se necessária uma avaliação constante da formação e função do sistema nervoso central já que ele é afetado pelo gene FMR-1 (acrônimo em inglês para Fragile X linked mental retardation type 1 ou atraso mental ligado ao X Frágil tipo 1). ${ }^{8,13}$ 
O comprometimento intelectual dos acometidos pela Síndrome pode ir de deficiência mental mediana até a deficiência mental profunda. Esses valores são definidos por meio do quociente de inteligência (QI). O indivíduo que apresentar QI acima de 70 pode ser considerado normal, já os que apresentam valores abaixo dessa média podem ser considerados com deficiência mental. ${ }^{8}$

Entre as características físicas da SXF estão: orelhas largas e proeminentes, normalmente com inserção baixa, face alongada, fronte larga (Figura 4), sobrancelhas grossas, prognatismo, palato alto arqueado, macrocefalia e macroorquidismo (aumento do tamanho dos testículos) em adolescentes do sexo masculino (Figura 5). ${ }^{13,17}$

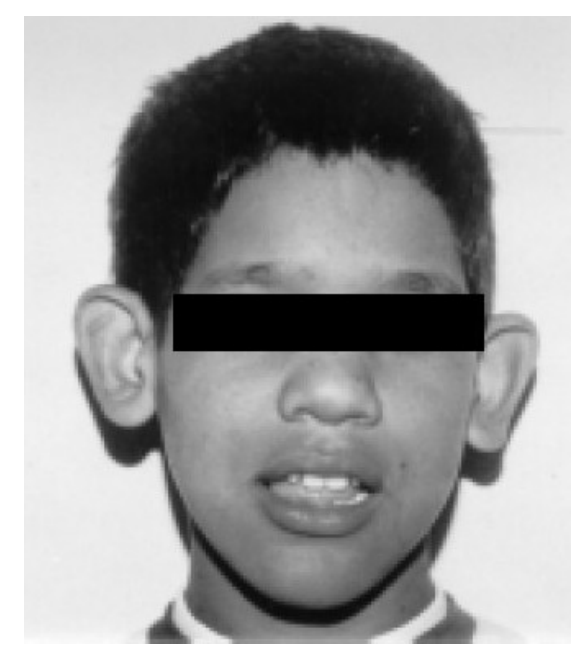

Figura 4 - Face alongada com orelhas grandes e proeminentes Fonte: Queiroz. ${ }^{18}$
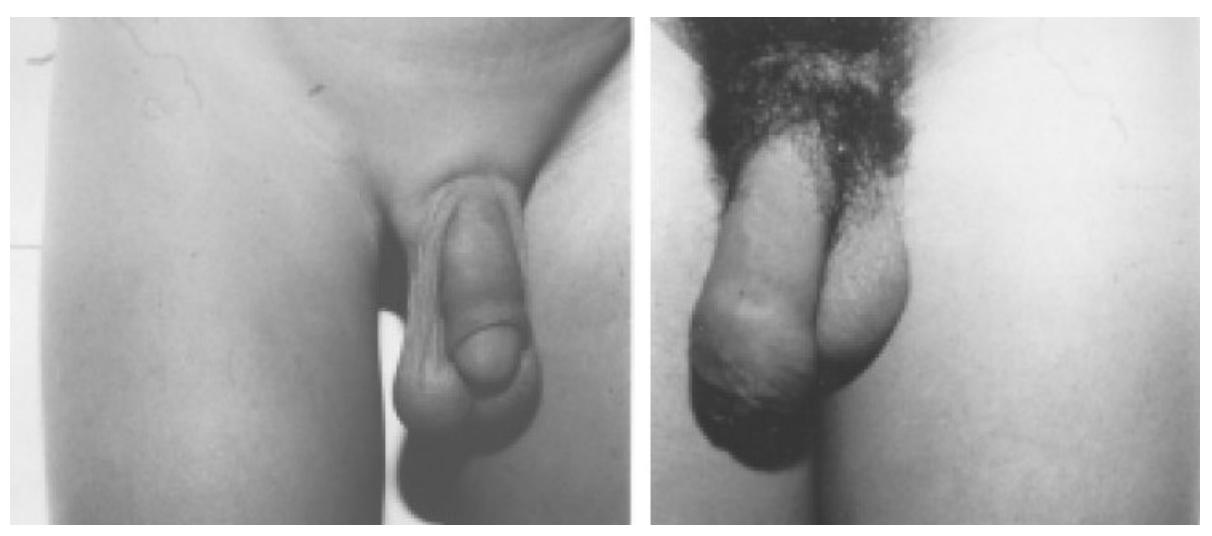

Figura 5 - Macroorquidismo em adolescentes do sexo masculino Fonte: Queiroz. ${ }^{18}$

As características físicas podem se manifestar desde o nascimento até a fase adulta. Em recém-nascidos nota-se a macrocefalia, a qual prejudica a mamada em razão de os indivíduos não possuírem força para sugar. Nas crianças, além do atraso psicomotor, evidenciam-se otites frequentes que dificultam a capacidade de distinguir sons, má oclusão dentária com o palato ogival, transtornos 
oculares, escolioses, pés planos, prolapso da válvula mitral, entre outras características. Em jovens e adultos é possível observar que o formato do rosto é mais alongado e apresentam mandíbula proeminente, orelhas maiores que o tamanho normal e macroorquidismo. ${ }^{15,17}$

\subsection{DIAGNÓSTICO}

Os testes para diagnóstico exato da Síndrome do X Frágil são considerados novos em razão de que eles foram desenvolvidos há pouco menos de 30 anos. Como a análise citogenética (Figura 6) não consegue identificar portadores da mutação completa ou da pré-mutação em mulheres, não é utilizada como método de diagnóstico, pois não oferece sensibilidade ou especificidade. ${ }^{13}$

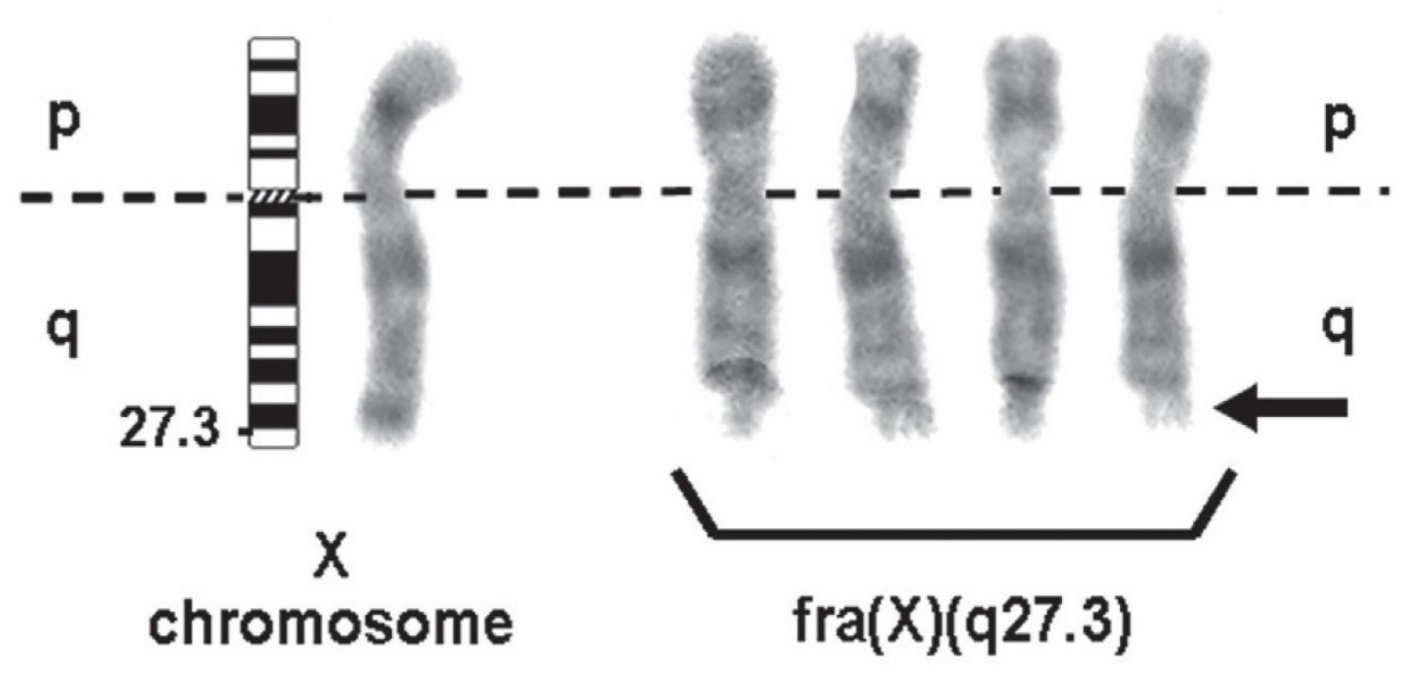

Figura 6 - Visualização de um cromossomo X normal e do sítio frágil do cromossomo X de indivíduo com Síndrome do X Frágil, região Xq27.3 (seta) em cariótipo (p: braço curto; q: braço longo) [fra(X)(q27.3)]

Fonte: Floriani, Boas, Rosa, Trevisan, Dorfman, Rosa, et al. ${ }^{19}$

A criação de testes moleculares que confirmam com quase absoluta certeza o diagnóstico de SXF somente foi possível após a identificação do gene FMR1, que aconteceu em 1991. Amostras de sangue, tecido e algumas células de líquido amniótico e vilosidades coriônicas podem ser utilizadas na análise molecular para um diagnóstico pré-natal. ${ }^{13}$

Grande parte dos laboratórios utiliza duas técnicas para a análise molecular do gene FMR1. A Reação em Cadeia da Polimerase (PCR), que se baseia na amplificação enzimática quantificando o "número exato de repetições CGG em situações normais e pequenas pré-mutações", ${ }^{13}$ é uma técnica rápida e que pode ser realizada com poucas quantidades de material genético. A outra técnica, rotineiramente utilizada, é a Southern blot, que permite obter um valor aproximado do número de repetições e determina o estado de metilação do gene FMR1. ${ }^{13}$ 
Uma combinação dos exames de PCR e Southern blot aumenta a confiabilidade do diagnóstico, podendo chegar a 99\% de certeza. O teste de PCR pode também ser usado como triagem quando há suspeita de SXF em crianças que apresentam retardo mental, uma vez que é um exame de rápida execução. ${ }^{1,19}$

O diagnóstico precoce da SXF tem extrema importância principalmente para realização do aconselhamento genético, identificando, assim, possíveis portadores ou afetados na família e prevenindo a aparição de novos casos. ${ }^{1}$

\subsection{TRATAMENTO}

Não existe cura para a Síndrome do X Frágil. Para melhorar a qualidade de vida dos indivíduos afetados são feitos tratamentos sintomáticos e acompanhamentos terapêuticos. Por meio da psicofarmacologia, medicamentos próprios são utilizados para amenizar ou acabar com alguns sintomas causados pela Síndrome. ${ }^{8}$

Faz-se necessário que o indivíduo tenha o acompanhamento de uma equipe multidisciplinar, formada por psicólogos, psiquiatras, fonoaudiólogos, psicopedagogos, terapeutas ocupacionais, fisioterapeutas, neurologistas, entre outros profissionais, os quais devem auxiliar o portador da Síndrome a se desenvolver da melhor forma possível para que, assim, possa ter a chance ingressar facilmente na sociedade. ${ }^{8,15}$

A família do portador da SXF tem um papel muito importante na sua integração social, considerando que ela pode facilitar ou impedir o ingresso à sociedade ou, até mesmo, a integração com a próprios familiares. ${ }^{8}$

\section{RELATO DE CASO E DISCUSSÃO}

Neste relato de caso objetivou-se apresentar as características físicas e os sintomas iniciais de uma criança com Síndrome do X Frágil a fim de auxiliar no diagnóstico de outros nascimentos de portadores da mesma Síndrome. O diagnóstico precoce possibilita o acompanhamento do indivíduo por psicólogos, fonoaudiólogos, fisioterapeutas, neurologistas e outros profissionais da área da saúde, que melhoram sua qualidade de vida e auxiliam na integração social.

Paciente S.M.F., do gênero feminino, branca, nasceu no dia 15 de junho de 2016, com aproximadamente 2.620 g e $48 \mathrm{~cm}$ de altura. Durante a anamnese, a mãe relatou ter tido uma gestação de 39 semanas, realizando o pré-natal desde o começo da gravidez. Foi diagnosticada com diabetes gestacional no $5^{\circ}$ mês da gestação e o controle foi feito apenas com dieta. No $8^{\circ}$ mês de gestação a mãe deu entrada na Unidade de Pronto Atendimento (UPA) de Patos de Minas, MG, sentindo cefaleia, febre e apresentando equimoses. Após exames sorológicos foi confirmado caso de dengue e tratado com analgésicos, antitérmicos e hidratação. 
A paciente nasceu por meio de cesárea e sem complicações. Um dia após o nascimento, mãe e filha receberam alta e foram para casa. Ao terceiro dia de vida, notou-se que a mãe não conseguia amamentar, apresentou alguns picos glicêmicos em razão da falta de alimentação e precisou de suplementação alimentar, porém não apresentou alterações físicas evidentes. Com 22 dias de vida, a paciente deu entrada na UPA apresentando febre. Foram realizados exames que diagnosticaram bronquiolite, e, durante a triagem, percebeu-se que ela havia ganhado menos de $100 \mathrm{~g}$, pesando apenas $2.700 \mathrm{~g}$, provavelmente em razão da dificuldade de sucção. Ficou internada por cinco dias para tratamento e, posteriormente, recebeu alta.

A mãe procurou aconselhamento pediátrico em razão da dificuldade de ganho de peso da paciente. Foi, então, solicitado o exame de ultrassom transfontanela para detectar hemorragias ou hidrocefalia e um ecocardiograma para averiguar o motivo do esforço cardíaco. Ambos apresentaram resultados negativos.

A paciente começou a apresentar atraso no desenvolvimento neuropsicomotor e hipotonia generalizada. Após exame externo mais detalhado, os médicos finalmente constataram alguns sinais físicos como a macrocefalia, pés planos e palato ogival. Em decorrência da suspeita de doença genética foi solicitado o exame de cariotipagem genética. $\mathrm{O}$ exame mostrou que o cariótipo feminino apresentava material adicional de origem desconhecida no cromossomo X ligado à banda Xq27 (46,X,add(X)(q27)), mas nem a origem do segmento extra nem o tipo do rearranjo puderam ser identificados. Aproximadamente aos cinco meses de idade a paciente recebeu o diagnóstico de Síndrome do X Frágil.

A partir do diagnóstico de SXF, a paciente começou acompanhamento com fisioterapeutas e fonoaudiólogos, ao menos uma vez por semana, para desenvolver mobilidade dos membros superiores e inferiores e habilidade de engolir.

No dia 7 de novembro de 2016, com quatro meses de vida, a paciente foi internada no Centro de Tratamento e Terapia Intensiva (CTI) de um hospital particular de Patos de Minas, MG, em razão de um quadro de hipotonia e pneumonia respiratória, diagnosticados mediante tomografia computadorizada do tórax (Figura 7); a paciente apresentava-se também hipoativa e hipocorada. Durante internação a paciente utilizou sonda nasogástrica para se alimentar, ganhando aproximadamente $1 \mathrm{~kg}$ (Figura 8). Antes da alimentação nasogástrica a paciente não conseguia manter o ganho de peso uma vez que a função de deglutição estava prejudicada.

\begin{tabular}{|c|c|}
\hline $\begin{array}{l}\text { Aspectos } \\
\text { observados }\end{array}$ & $\begin{array}{l}\text { Consolidação basal medial à esquerda que, mediante correlação clínico-propedêutica, pode estar } \\
\text { associada à penumopatia inflamatória; } \\
\text { Áreas de atenuação em vidro-fosco bilaterais inespecíficas; } \\
\text { Sem evidências de alteração pleural; } \\
\text { Cúpulas e seios costofrênicos livres; } \\
\text { Hilos e vascularização pulmonar normais; } \\
\text { Mediastino de configuração anatômica; } \\
\text { Sem evidências de linfonodomegalia mediastinal; } \\
\text { Traqueia e brônquios principais de aspecto tomográfico normal; } \\
\text { Vasos da base com calibre e em topografia habituais. }\end{array}$ \\
\hline Conclusão & $\begin{array}{l}\text { Consolidação basal medial à esquerda que, mediante correlação clínico-propedêutica, pode estar } \\
\text { associada à pneumopatia inflamatória. }\end{array}$ \\
\hline
\end{tabular}

Figura 7 - Tomografia computadorizada do tórax do paciente 


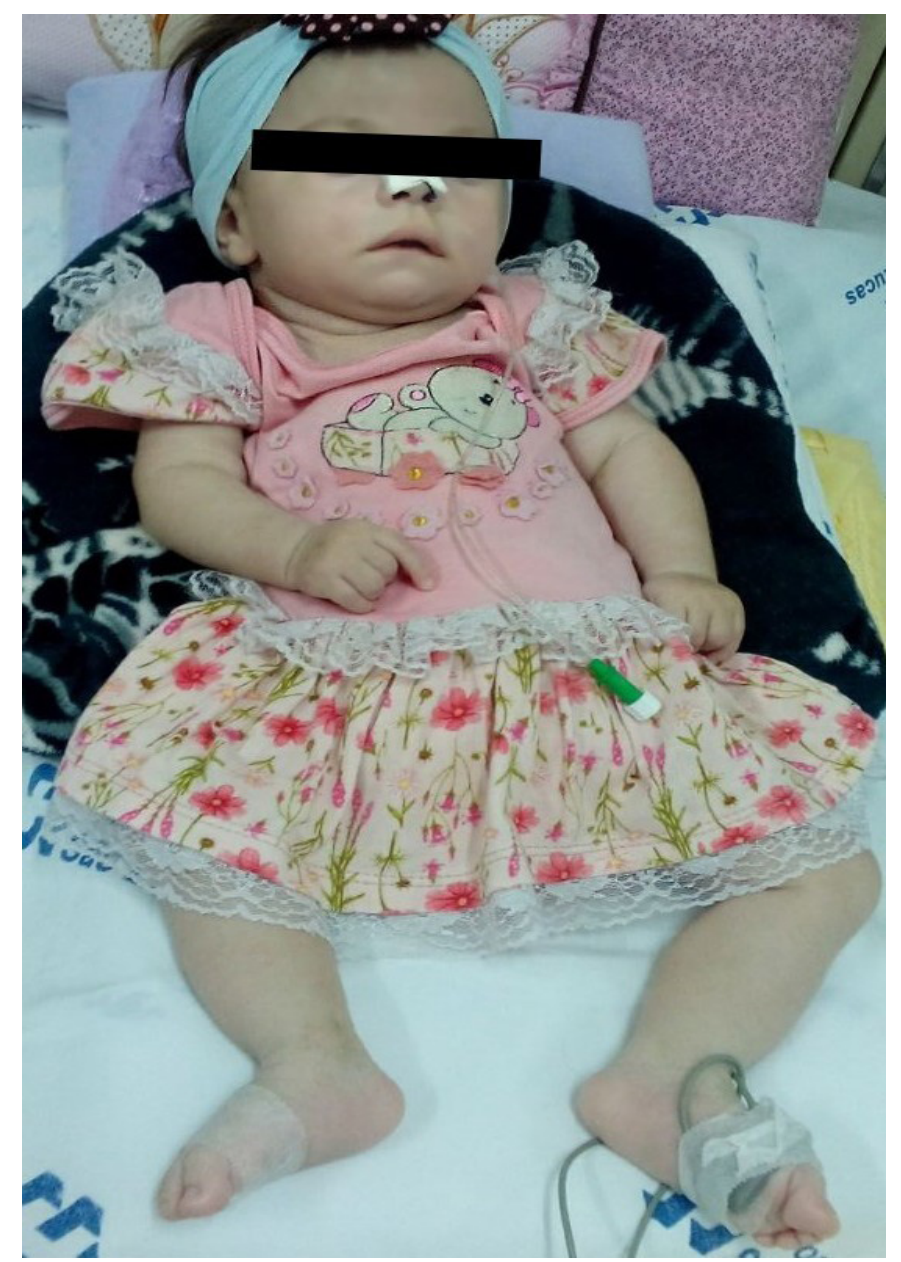

Figura 8 - Paciente utilizando sonda nasogástrica

Foi feito hemograma completo, Proteína C Reativa (PCR), dosagens de cálcio, cloretos, magnésio, potássio, sódio e hemocultura (Tabela 1). Foram encontrados valores abaixo dos normais de hemoglobina e hamatócrito (indicando uma anemia normo/normo) e leucócitos segmentados. A paciente apresentou duas paradas cardiorrespiratórias durante o período de internação, ambas revertidas com massagem cardíaca, não havendo necessidade de intubação. Após realizar radiografias e tomografias constatou-se que os órgãos do lado esquerdo eram menos desenvolvidos que os do lado direito, e a paciente apresentava atrofia cerebral o que afetava sua função neurológica (Figura 9). 
Tabela 1 - Exames laboratoriais da paciente em sua internação na CTI com 4 meses de vida ${ }^{\dagger}$

\begin{tabular}{|c|c|}
\hline Tipo do exame & Detalhamento \\
\hline Eritograma & $\begin{array}{l}\text { Hemácias: } 4,11 \text { milhões } / \mathrm{mm}^{3} \\
\text { Hemoglobina: } 10,6 \mathrm{~g} / \mathrm{dL} \\
\text { Hematócrito: } 32,3 \% \\
\text { VCM: } 78,6 \mathrm{fL} \\
\text { HCM: } 25,8 \mathrm{pg} \\
\text { CHCM: } 32,8 \% \\
\text { RDW: } 13,2 \%\end{array}$ \\
\hline Leucograma & $\begin{array}{l}\text { Global: } 13900 / \mathrm{mm}^{3} \\
\text { Basófilos: } 111 / \mathrm{mm}^{3} \\
\text { Eosinófilos: } 792 / \mathrm{mm}^{3} \\
\text { Mielócitos: } 0 / \mathrm{mm}^{3} \\
\text { Metamielócitos: } 0 / \mathrm{mm}^{3} \\
\text { Bastonetes: } 0 / \mathrm{mm}^{3} \\
\text { Segmentados: } 4476 / \mathrm{mm}^{3} \\
\text { Linfócitos Típicos: } 7617 / \mathrm{mm}^{3} \\
\text { Linfócitos Atípicos: } 0 / \mathrm{mm}^{3} \\
\text { Monócitos: } 904 / \mathrm{mm}^{3}\end{array}$ \\
\hline Plaquetas & $282000 / \mathrm{mm}^{3}$ \\
\hline Proteína C Reativa $^{a}$ & $1 \mathrm{mg} / \mathrm{dL}$ \\
\hline Hemocultura ${ }^{\mathrm{b}}$ & Negativo após 5 dias de incubação \\
\hline Cálcio $^{c}$ & $9,5 \mathrm{mg} / \mathrm{dL}$ \\
\hline Cloretos $^{\mathrm{d}}$ & $112 \mathrm{mEq} / \mathrm{L}$ \\
\hline Magnésio $^{\mathrm{e}}$ & $2,32 \mathrm{mg} / \mathrm{dL}$ \\
\hline Potássio $^{d}$ & $5,2 \mathrm{mEq} / \mathrm{L}$ \\
\hline Sódio $^{\mathrm{d}}$ & $139 \mathrm{mEq} / \mathrm{L}$ \\
\hline
\end{tabular}

Tabela 2 - Tomografia computadorizada de crânio

Arcabouço ósseo íntegro;

Sem evidências de processo expansivo intracraniano ou de coleção intra ou extra-axial acima ou abaixo do tentório;

Aspectos observados

Alargamento das fissuras de Sylvius, cisternas da base e dos sulcos entre os giros corticais.

As substâncias branca e cinzenta mostram coeficientes de atenuação normais;

Dilatação dos ventrículos laterais e do terceiro ventrículo. O quarto ventrículo

está com morfologia, dimensões e em topografia habituais;

Não há desvio da linha média.

Conclusão

Redução volumétrica dos hemisférios cerebrais.

Apesar da pouca função neurológica a paciente era capaz de reconhecer vozes e fisionomias, apresentava reduzido movimento dos membros superiores, mexendo pouco os braços e não abria as mãos; já seus membros inferiores não se movimentavam.

Após mais de 30 dias internada, com 6 meses de vida, a paciente apresentou melhora, podendo ser levada para casa para receber cuidados especiais. A alimentação nasogástrica foi mantida e não

${ }^{\dagger}$ a: método de turbidimetria; b: isolamento em meios de cultura e identificação; c: colorimétrico arsenazo III; d: eletrodo seletivo; e: colorimétrico - calmagite. 
houve necessidade de intubação. No sétimo dia em casa, a paciente teve nova parada cardiorrespiratória, precisando retornar ao hospital, onde permaneceu internada (Figura 10).

Ao dar entrada no hospital a paciente encontrava-se hipoativa, hiporreativa, com abdômen globoso, sem desenho de alças, doloroso e tenso. O hemograma completo e dosagens de Proteína C Reativa (PCR), cálcio, cloretos, magnésio, sódio e potássio encontram-se na Tabela 2.

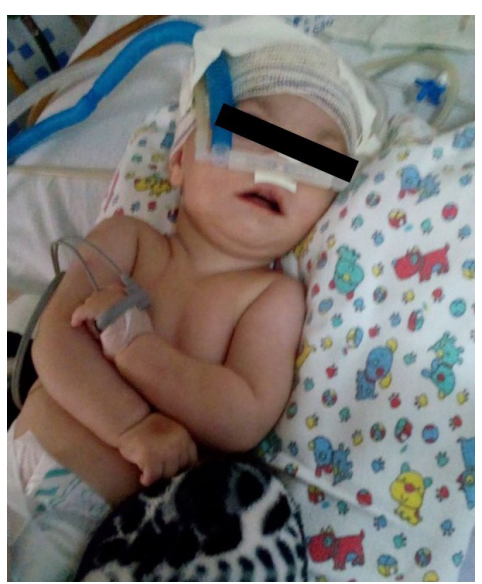

Figura 9 - Paciente internada após parada cardiorrespiratória, com seis meses de vida

Tabela 3 - Exames laboratoriais da paciente em sua internação na CTI com 6 meses de vida *

\begin{tabular}{|c|c|}
\hline Tipo do exame & Detalhamento \\
\hline Eritograma & $\begin{array}{l}\text { Hemácias: } 4,32 \text { milhões/mm3 } \\
\text { Hemoglobina: } 11,3 \mathrm{~g} / \mathrm{dL} \\
\text { Hematócrito: } 33,4 \% \\
\text { VCM: } 77,3 \mathrm{fL} \\
\text { HCM: } 26,2 \mathrm{pg} \\
\text { CHCM: } 33,8 \% \\
\text { RDW: } 15,1 \%\end{array}$ \\
\hline Leucograma & $\begin{array}{l}\text { Global: } 18600 / \mathrm{mm} 3 \\
\text { Basófilos: } 0 / \mathrm{mm} 3 \\
\text { Eosinófilos: } 0 / \mathrm{mm} 3 \\
\text { Mielócitos: } 0 / \mathrm{mm} 3 \\
\text { Metamielócitos: } 0 / \mathrm{mm} 3 \\
\text { Bastonetes: } 186 / \mathrm{mm} 3 \\
\text { Segmentados: } 7626 / \mathrm{mm} 3 \\
\text { Linfócitos Típicos: } 9858 / \mathrm{mm} 3 \\
\text { Linfócitos Atípicos: } 0 / \mathrm{mm} 3 \\
\text { Monócitos: } 930 / \mathrm{mm} 3\end{array}$ \\
\hline Plaquetas & $707000 / \mathrm{mm} 3$ \\
\hline Proteína C Reativa ${ }^{a}$ & $1,1 \mathrm{mg} / \mathrm{dL}$ \\
\hline Cálcio ${ }^{\mathrm{b}}$ & $10,5 \mathrm{mg} / \mathrm{dL}$ \\
\hline Cloretos $^{c}$ & $95 \mathrm{mEq} / \mathrm{L}$ \\
\hline Magnésio $^{\mathrm{d}}$ & $2,28 \mathrm{mg} / \mathrm{dL}$ \\
\hline Potássio ${ }^{c}$ & $5,7 \mathrm{mEq} / \mathrm{L}$ \\
\hline Sódio $^{c}$ & $131 \mathrm{mEq} / \mathrm{L}$ \\
\hline
\end{tabular}

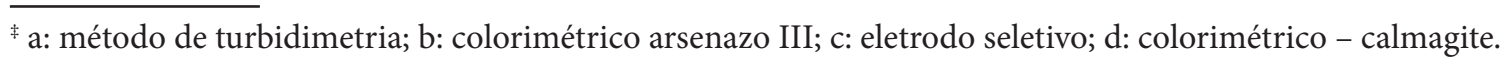


No dia 25 de dezembro de 2016, a paciente foi a óbito em razão de uma insuficiência respiratória crônica ligada à Síndrome do X Frágil.

A Síndrome do X Frágil é uma causa considerável de retardo mental ligada à hereditariedade e apresenta diversas manifestações físicas e psicomotoras. A sintomatologia é mais evidente em pacientes do sexo masculino, possivelmente por apresentarem apenas um cromossomo X, o qual é defeituoso, fazendo da paciente do relato um exemplo raro de portador da SXF.,

Neste relato foram documentadas diversas alterações físicas relacionadas com a Síndrome, como: hipotonia, limitada capacidade de movimentação, pés planos, macrocefalia e palato alto arqueado que dificultava a sucção prejudicando a nutrição da paciente. Diversas vezes a paciente apresentou-se hipoativa e hipocorada, o que, associado aos baixos valores de hemoglobina e hematócrito, pode ser indicativo de anemia de caráter ferroprivo. O baixo valor de leucócitos segmentados possivelmente indica um sistema imune ainda não maduro, que pode ter contribuído para o quadro de pneumapatia inflamatória (infecção pulmonar contagiosa). ${ }^{8,9,11,12,14}$

Pacientes com a Síndrome frequentemente desenvolvem prolapso da válvula mitral, o que, com a dissimetria dos órgãos, pode ter contribuído para as paradas cardiorrespiratórias. ${ }^{11,14,18}$

Em decorrência de algumas complicações relacionadas à SXF a paciente foi a óbito com 6 meses e 10 dias de vida, não podendo, assim, apresentar outras manifestações clínicas condizentes com a Síndrome, as quais geralmente ocorrem à medida que o indivíduo se desenvolve. Normalmente, decorrem até 16 meses entre o aparecimento dos primeiros sintomas, que são inespecíficos, até a conclusão do diagnóstico. No caso em estudo, o diagnóstico precoce da Síndrome na paciente (aos cinco meses de idade) foi de extrema importância não apenas para que ela pudesse ter acompanhamento multidisciplinar, mas também para a família, que fará mapeamento genético com o objetivo de evitar o aparecimento de novos casos. ${ }^{16}$

\section{CONSIDERAÇÕES FINAIS}

A Síndrome do X Frágil é a segunda causa genética mais comum para o retardo mental e a primeira de caráter herdado, portanto, não há cura. O diagnóstico inicial torna-se necessário para que os indivíduos acometidos pela SXF possam ser acompanhados por profissionais qualificados, a fim de incluí-los na sociedade e melhorar sua qualidade de vida.

Para que ocorra o diagnóstico precoce é importante que familiares e profissionais da área da saúde atentem aos sinais e sintomas tanto físicos quanto psicológicos que, por não serem específicos dessa Síndrome, podem ser confundidos com outros tipos de atraso ou retardo mental. Em razão dos sintomas inespecíficos, o diagnóstico é essencialmente molecular; após seu fechamento é interessante que familiares próximos ao paciente portador da Síndrome recebam aconselhamento genético a fim de evitarem aparecimento de novos casos. 


\section{REFERÊNCIAS}

1. Veiga MF, Toralles MBP. A expressão neurológica e o diagnóstico genético nas síndromes de Angelman, de Rett e do X-Frágil. J Pediatr. [Internet]. 2002 [citado 2017 nov 4]; 78(1 Supl):S55-62. Disponível em: http://www.scielo.br/scielo.php?script=sci_abstract\&pid=S0021$-75572002000700009 \& \operatorname{lng}=\mathrm{en} \& \mathrm{nrm}=\mathrm{iso} \& \operatorname{lng}=\mathrm{pt}$

2. França DCC, Maria DMC, Corrêa IPC, Aburad ATT, Aguiar SMHCÁ. Síndrome do X Frágil. Revista Faipe [Internet]. 2017 jun 10 [citado 2017 nov. 4]; 1(1):1-5. Disponível em: http://revistafaipe.lifesistemas.com.br/index.php/RFAIPE/article/view/1

3. Rodrigueiro DA. Síndrome do cromossomo X frágil: análise intrafamilial das características clínicas, psicológicas, fonoaudiológicas e moleculares [tese] [Internet]. Botucatu: Universidade Estadual Paulista; 2006. [citado 2017 nov 4]. Disponível em: http://www2.ibb.unesp.br/posgrad/teses/ genetica_do_2006_debora_rodrigueiro.pdf

4. Volpato S, Anrain BC, Lanzzarin C, Bizzotto JF, Cachoeira SF, Frey MG, et al. Síndrome do X Frágil: um breve referencial teórico. Ação Odonto [Internet]. 2013 [citado 2017 nov 4]; 1(1):109-16. Disponível em: https://editora.unoesc.edu.br/index.php/acaodonto/article/view/3863

5. Franco V. Síndrome do X frágil: pessoas, contextos \& percursos [Internet]. 1st ed. Évora: Edições Aloendro; 2013. [citado 2017 nov 4]. Disponível em: https://dspace.uevora.pt/rdpc/bitstream/10174/9926/1/livro_sxf.pdf

6. Boy R, Correia PS, Llerena JC, Machado-Ferreira MC, Pimentel MMG. Síndrome do X frágil: estudo caso-controle envolvendo pacientes pré e pós-puberais com diagnóstico confirmado por análise molecular. Arq. Neuro-Psiquiatr. [Internet]. 2001 [citado 2017 nov 4]; 59(1):83-8. Disponível em: http://www.scielo.br/scielo.php?script=sci_abstract\&pid=S0004-282X2001000100017\&lng $=\mathrm{en} \& \mathrm{nrm}=\mathrm{iso} \& \mathrm{t} \operatorname{lng}=\mathrm{pt}$

7. Laboratório Gene. X-Frágil Citogenético (Cariótipo) - Exames realizados pelo Laboratório Gene. Laboratório Gene [Internet]. 2015 [citado 2017 nov 4]. Disponível em: http://www.laboratoriogene.com.br/exames/x-fragil-citogenetico-cariotipo/

8. Centro de pesquisa sobre o genoma humano e células-tronco. Síndrome do cromossomo X frágil. Projeto Genoma [Internet]. [citado 2017 nov 4]. Disponível em: http://www.genoma.ib.usp.br/pt-br/servicos/consultas-e-testes-geneticos/doencas-atendidas/sindrome-do-cromossomo-x-fragil

9. Gómez MKA, Acosta AX. Aspectos gerais da Síndrome do X-Frágil: principal causa hereditária de retardo mental. R. Ci. Méd. Biol. [Internet]. 2007 [citado 2017 nov 4]; 6(2):197-203. Disponível em: https://portalseer.ufba.br/index.php/cmbio/article/view/4350

10. Mingarro Castillo MM, Ejarque Doménech I, García Moreno A, Aras Portilla LM. Síndrome del cromosoma X frágil. Rev. Clín. Med. Fam. [Internet]. 2017 [citado 2017 nov 4]; 10(1):54-7. Disponível em: http://scielo.isciii.es/scielo.php?script=sci_abstract\&pid=S1699-695X2017000100 011\&lng=es\&nrm=iso\&tlng=es 
11. Amaral COF, Sollitto KC, Santos TMD, Parizi AGS, Oliveira A, Straioto FG. Características físicas e bucais em pacientes portadores da Síndrome do X-Frágil. Rev. Assoc. Paul. Cir. Dent. [Internet]. 2012 [citado 2017 nov 4]; 66(2):128-35. Disponível em: http://revodonto.bvsalud.org/ scielo.php?script=sci_abstract\&pid=S0004-52762012000200007\&lng=es\&nrm=iso\&tlng=pt

12. Rosso TRF, Dorneles BV. Contagem numérica em estudantes com síndromes de X-Frágil e Prader-Willi. Rev. Bras. Educ. Espec. [Internet]. 2012 [citado 2017 nov 4]; 18(2):231-44. Disponível em: http://www.scielo.br/scielo.php?script=sci_abstract\&pid=S1413-65382012000200005\&ln $\mathrm{g}=\mathrm{en} \& \mathrm{nrm}=\mathrm{iso} \& \operatorname{lng}=\mathrm{pt}$

13. Hessl D, Grigsby J. Fragile X-associated tremor/ataxia syndrome: another phenotype of the fragile X gene. Clin. Neuropsychol. [Internet]. 2016 [cited 2017 Nov 4]; 30(6):810-4. Available from: http://dx.doi.org/10.1080/13854046.2016.118666

14. Stegani FC. Desafios na avaliação genético-molecular de pacientes com suspeita da síndrome do x-frágil atendidos na rede pública de saúde do estado de Goiás [dissertação] [Internet]. Goiânia: Pontifícia Universidade Católica de Goiás; 2011. [citado 2017 nov 4]. Disponível em: http:// tede2.pucgoias.edu.br:8080/handle/tede/2335

15. Christofolini DM, Pinheiro FS, Bianco B, Melaragno MI, Ramos MA de P, Brunoni D, et al. Síndrome de tremor e ataxia associada ao X frágil: rastreamento por PCR em amostra de idosos. Arq Bras Ciên Saúde [Internet]. 2009 Abr 30 [citado 2017 nov 4]; 34(1):22-6. Disponível em: https://www.portalnepas.org.br/abcs/article/view/141

16. Bailey DB, Raspa M, Bishop E, Holiday D. No Change in the Age of Diagnosis for Fragile X Syndrome: Findings From a National Parent Survey. Pediatrics [Internet]. 2009 [cited 2017 Nov 4]; 124(2):527-33. Available from: http://pediatrics.aappublications.org/content/124/2/527

17. Modesto AM, Aguiar MFM, Barbosa H, Vilela SSL, Santos M, Ferrari I, et al. Síndrome do X frágil: relato de caso em dois irmãos. J Pediatr. [Internet]. 1997 [citado 2017 nov 4]; 73(6):419-22. Available from: http://www.jped.com.br/Redirect.aspx?varArtigo=572

18. Queiroz MA. Avaliação de pré-mutação por PCR na síndrome do X frágil [dissertação] [Internet]. Florianópolis: Universidade Federal de Santa Catarina; 2006. [citado 2017 nov 4]. Disponível em: https://repositorio.ufsc.br/xmlui/handle/123456789/88478

19. Floriani MA, Boas MRV, Rosa RFM, Trevisan P, Dorfman LE, Rosa RCM, et al. Relato de um paciente com a síndrome do X frágil identificada de forma inesperada por meio do cariótipo. J Bras Patol Med Lab. [Internet]. 2017. [citado 2017 nov 4]; 53(2):108-9. Disponível em: http:// www.scielo.br/scielo.php?script=sci_abstract\&pid=S1676-24442017000200108\&lng=en\&nrm $=\mathrm{is}$ o\&tlng=en

Data da submissão: 27 de outubro de 2017 Avaliado em: 04 de novembro de 2017 (AVALIADOR A) Aceito em: 06 de novembro de 2017 